\title{
CO2 Reduction on an Iron-Porphyrin Center: A Computational Study
}

\section{DOI:}

10.1021/acs.jpca.9b05102

\section{Document Version}

Accepted author manuscript

Link to publication record in Manchester Research Explorer

\section{Citation for published version (APA):}

Davethu, P. A., \& De Visser, S. P. (2019). CO2 Reduction on an Iron-Porphyrin Center: A Computational Study. The Journal of Physical Chemistry A. https://doi.org/10.1021/acs.jpca.9b05102

\section{Published in:}

The Journal of Physical Chemistry A

\section{Citing this paper}

Please note that where the full-text provided on Manchester Research Explorer is the Author Accepted Manuscript or Proof version this may differ from the final Published version. If citing, it is advised that you check and use the publisher's definitive version.

\section{General rights}

Copyright and moral rights for the publications made accessible in the Research Explorer are retained by the authors and/or other copyright owners and it is a condition of accessing publications that users recognise and abide by the legal requirements associated with these rights.

\section{Takedown policy}

If you believe that this document breaches copyright please refer to the University of Manchester's Takedown Procedures [http://man.ac.uk/04Y6Bo] or contact uml.scholarlycommunications@manchester.ac.uk providing relevant details, so we can investigate your claim.

\section{OPEN ACCESS}




\title{
$\mathrm{CO}_{2}$ Reduction on an Iron-Porphyrin Center: A Computational Study
}

\author{
Paul A. Davethu ${ }^{\ddagger}$ and Sam P. de Visser*‡ \\ ‡ The Manchester Institute of Biotechnology and School of Chemical Engineering and Analytical Science, the Univer- \\ sity of Manchester, 131 Princess Street, Manchester MI 7DN, United Kingdom.
}

ABSTRACT: Carbon dioxide is a greenhouse gas and available with large abundance in the atmosphere. Because of this many researchers have searched for opportunities to utilize $\mathrm{CO}_{2}$ and convert it into valuable materials. In this work we study the electrochemical reduction of $\mathrm{CO}_{2}$ to $\mathrm{CO}$ on an iron-porphyrin center using computational modelling. We tested two types of iron-porphyrins, namely the tetraphenylporphyrin (TPP) and meso-(ortho-2-amide-phenyl)(triphenyl)porphyrin ligands. Density functional theory calculations investigated a catalytic cycle that involves a reduction, $\mathrm{CO}_{2}$ binding, two protonation and another reduction step. We tested several density functional theory methods, basis sets and model structures. There is a certain degree of variation between the results obtained with different density functional methods, but the same general trends are found. The calculations show that during the reduction processes a ligand rather than metal reduction takes place, which enables stable binding of $\mathrm{CO}_{2}$ as an $\left[\mathrm{Fe}^{\prime \prime \prime}\left(\mathrm{CO}_{2}{ }^{2-}\right)\left(\mathrm{TPP}^{-*}\right)\right]^{2-}$ complex. The subsequent proton transfer from phenol has a small barrier and is identified as a proton-coupled electron-transfer process, while the second proton transfer does not change the electronic configuration of the metal complex. Overall, the studies show that iron porphyrins are efficient $\mathrm{CO}_{2}$ reducing systems that should be able to turnover $\mathrm{CO}_{2}$ into $\mathrm{CO}$ efficiently. Second-coordination sphere perturbations influence $\mathrm{CO}_{2}$ positioning, but are not seen to have electronic or thermochemical effects on the overall reaction mechanism.

Introduction.

Industrialization and the extensive use of fossil fuels has led to a steady increase of the $\mathrm{CO}_{2}$ concentration in the atmosphere over the past century. Scientists, therefore, are searching for technological applications to trap and convert $\mathrm{CO}_{2}$ from the atmosphere into value-added materials. Nature has a range of enzymes available that utilize carbon dioxide from the air and convert it back into useful chemicals, including, for instance, through the Calvin cycle, the reductive citric acid cycle, and the reductive acetyl CoA route. ${ }^{1-3}$ Over the past few decades a number of potentially useful synthetic catalysts have been identified for efficient $\mathrm{CO}_{2}$ reduction processes. ${ }^{4-6}$ Some of those work in tandem with water oxidation processes in an electrochemical cell, ${ }^{7,8}$ whereas others operate through photochemical activation processes. ${ }^{9}$

Although many $\mathrm{CO}_{2}$ reduction catalysts have been identified, they often use heavy metals and hence are toxic and expensive. ${ }^{10,11}$ Obviously, the ideal $\mathrm{CO}_{2}$ reduction catalyst is environmentally benign and typically should use a first-row transition metal. As such, in recent years studies have been devoted to the properties and characterization of iron and manganese based complexes and particular with metal-porphyrin systems good progress has been made. ${ }^{12-15}$ These systems have been shown to reduce $\mathrm{CO}_{2}$ to $\mathrm{CO}$ or formate but occasionally also react through a disproportionation reaction to form carbonate. ${ }^{16}$ Thus, the iron-tetraphenylporphyrin [Fe(TPP)] $]^{-}$system, Scheme 1, is a biomimetic model of heme enzymes, including the cytochromes P450 and peroxidases. These enzymes are highly versatile, and through the use of molecular oxygen react with substrates via oxygen atom transfer. ${ }^{17-20}$ Biomimetic models of the P450s and peroxidases have been extensively studied as a model to understand enzymatic reaction mechanisms. ${ }^{21-23}$ These biomimetic models were shown to react efficiently with terminal oxidants such as $\mathrm{H}_{2} \mathrm{O}_{2}$ that enabled oxygen atom transfer reactions to substrates. ${ }^{24,25}$ Further studies on these iron-porphyrin complexes identified a variety of additional reaction pathways and as such they were found to be able to reduce $\mathrm{CO}_{2}$ as well. ${ }^{26,27}$ As the $\mathrm{CO}_{2}$ reduction reaction to $\mathrm{CO}$ needs a proton source, it has been suggested to replace the porphyrin scaffold, or particularly, the periphery substituents of the porphyrin group with a polar group that can assist in those proton deliveries. Therefore, modified porphyrins 
were synthesized with one of the tetraphenyl groups at the meso-position of the porphyrin in [Fe(TPP)] replaced by hangman or urea-based ligands. Indeed, these ironporphyrins were able to reduce $\mathrm{CO}_{2}$ effectively that was ascribed to their proton-relay assistance mechanism. ${ }^{28,29}$

A recent model to the theme of substituted TPP ligand systems comes from Chang et a ${ }^{30}$ who incorporated amide groups on the phenyl substituents. Particularly, the [Fe(ortho-2-amide-TPP)] complex with ortho-2-amide-TPP $=$ meso-(ortho-2-amide-phenyl)(triphenyl)porphyrin) (Scheme 1) was shown to be a very effective $\mathrm{CO}_{2}$ reduction catalyst. However, little is known on how the ortho-2amide group interacts with the porphyrin and why this particular system reacts with $\mathrm{CO}_{2}$. Therefore, we decided to do a detailed computational study into the mechanism and electronic features of $\mathrm{CO}_{2}$ reduction on iron-porphyrin manifolds.
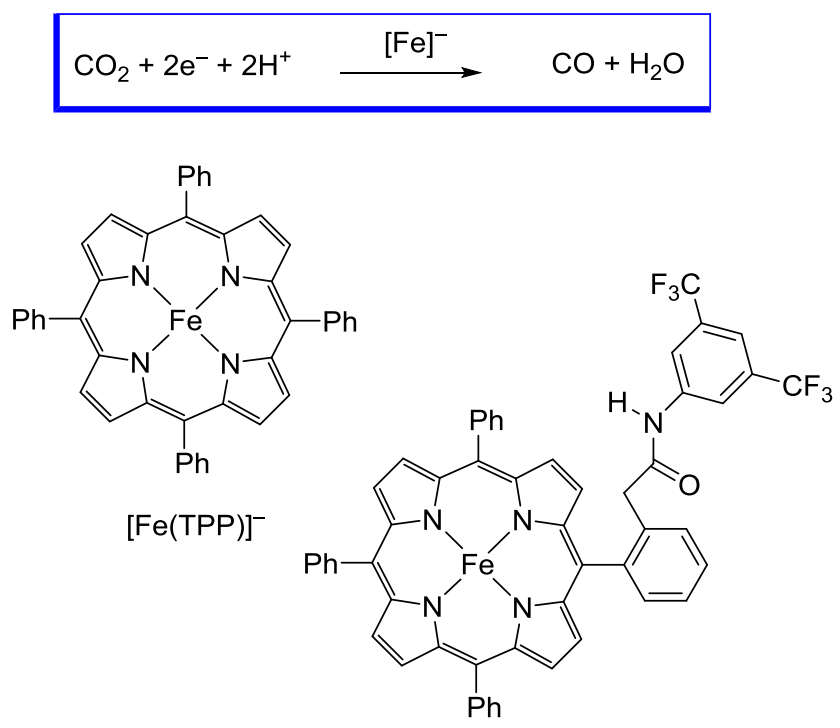

[Fe(ortho-2-amide-TPP)]

Scheme 1. Reaction and models investigated in this work.

In the past, we extensively studied monoxygenation reactions by iron-porphyrins and particularly looked into the mechanistic reaction profiles of oxygen atom transfer by P450 Compound I to substrates. ${ }^{31-33}$ These studies highlighted, for instance, effects of the second-coordination sphere through hydrogen bonding interactions. ${ }^{34,35}$ In order to gain insight into the second coordination sphere effect of hangman-porphyrins and the nature and the properties of the reductant involved in $\mathrm{CO}_{2}$ reduction we decided to study the $\mathrm{CO}_{2}$ reduction by the $[\mathrm{Fe}(\mathrm{TPP})]^{-}$and [Fe(ortho-2-amide-TPP)] systems. The work highlights how the ligand assists in $\mathrm{CO}_{2}$ positioning and the reduction of it into $\mathrm{CO}$.
Methods.

A series of density functional theory calculations were performed on the $\mathrm{CO}_{2}$ reduction cycle as described in Scheme 2, which is based on the chemical system proposed by Chang et al. ${ }^{30}$ Their system includes an iron atom embedded into a porphyrin macrocycle with an ortho2-amide group bound to one of the TPP linkages of the porphyrin scaffold. We investigated two models for the equatorial porphyrin ligand system, namely with a tetraphenylporphyrin (TPP) group and a ligand with monoortho-2-amide-linked tetraphenylporphyrin, namely (ortho-2-amide)TPP. Next, full geometry optimizations of the local minima along the reaction cycle in Scheme 2 were studied. These calculations were run without symmetry or geometric constraints and utilize density functional methods as implemented in Gaussian-09. ${ }^{36}$ We tested three different density functional methods, namely the unrestricted B3LYP, ${ }^{37,38}$ PBEO $^{39}$ and B3LYP-D3 ${ }^{37,38,40}$ methods. Initial optimizations utilized the LANL2DZ basis set (with core potential) on iron and $6-31 G^{*}$ on the rest of the atoms: basis set BS1. ${ }^{41,42}$ Single point calculations (BS2 basis set) were done with a triple- $\zeta$ quality LACV $3 P+$ basis set (with core potential) on iron and $6-311+G^{*}$ on the rest of the atoms. All calculations (including the geometry optimizations and frequencies) were run with a solvent model, i.e. the Continuum Polarized Conductor Model (CPCM), with a dielectric constant mimicking acetonitrile. ${ }^{43}$

As iron complexes have close-lying electronic and spin states, we calculated all structures in a range of lowenergy spin states. In general, the spin state ordering and relative energies gave little fluctuations between the different density functional theory methods and reproduced the ordering. Full details of the spin state energetics are given in the Supporting Information, while we focus on the low energy pathways only in the main text. Our methods and procedures are analogous to those previously reported and tested, which reproduced experimental free energies of activation and spectroscopic parameters well. ${ }^{44-47}$

To compliment the work, we created models of the $\left[\mathrm{Fe}\left(\mathrm{CO}_{2}\right)(\mathrm{L})\right]^{2-}$ and $[\mathrm{Fe}(\mathrm{C}(\mathrm{OH}) \mathrm{O})(\mathrm{L})]^{-}$complexes with $\mathrm{L}=\mathrm{TPP}$ or ortho-2-amide-TPP with a nearby phenol molecule included and studied the kinetics of the two proton transfer reaction steps in the catalytic cycle. Transition states were characterized by a frequency calculation that gave a single imaginary mode for the proton transfer motion. Free energies include zero-point, thermal and entropic corrections calculated at $298 \mathrm{~K}$. 


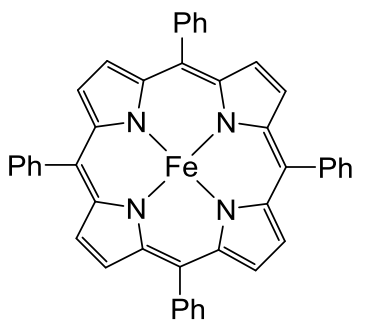

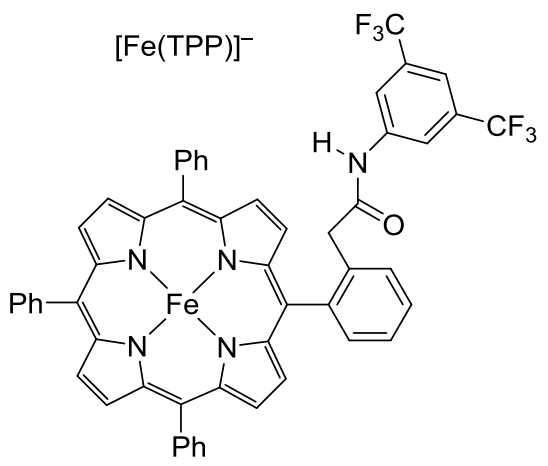

[Fe(ortho-2-amide-TPP)]
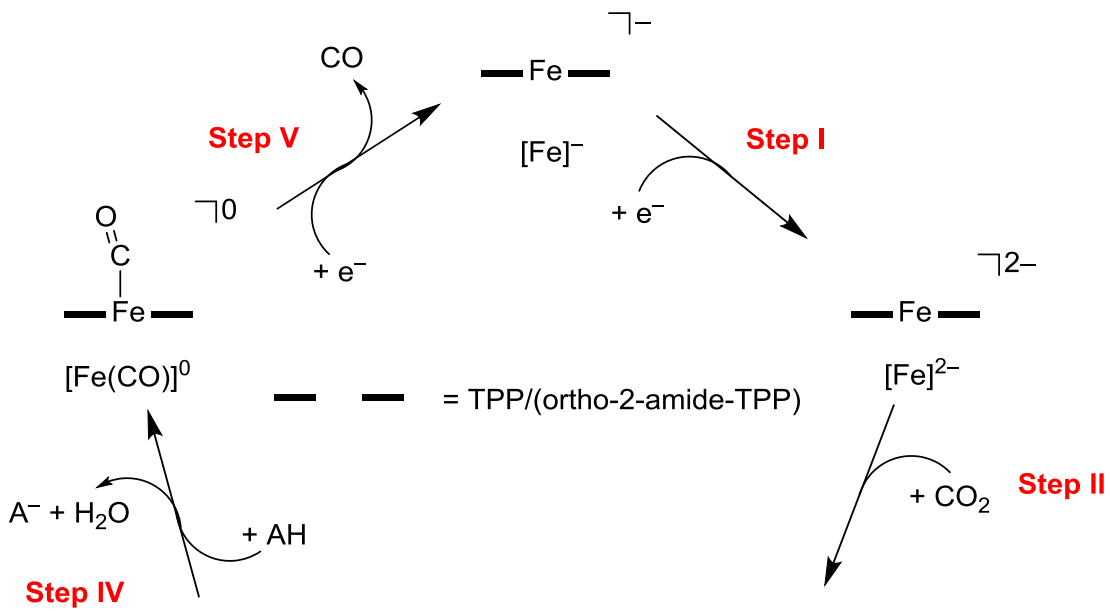

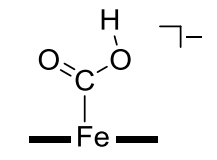

$[\mathrm{Fe}(\mathrm{C}(\mathrm{OH}) \mathrm{O})]^{-}$

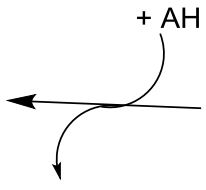

Step III

Scheme 2. Catalytic cycle for $\mathrm{CO}_{2}$ reduction by iron-porphyrins with definition of structures.

\section{Results and Discussion.}

Our initial studies focused on the catalytic cycle and the energies of each of the individual reaction steps as described in Scheme 2. The cycle starts from a formal iron(l)porphyrin complex, designated $[\mathrm{Fe}]^{-}$with either the TPP or ortho-2-amide-TPP ligand system. Next the complex is reduced to form the doubly negative complex, $[\mathrm{Fe}]^{2-}$, and binds $\mathrm{CO}_{2}$ to give the bound complex $\left[\mathrm{Fe}\left(\mathrm{CO}_{2}\right)\right]^{2-}$. Thereafter, a proton-donor $(\mathrm{AH})$ approaches the complex and delivers a proton to the complex to give $[\mathrm{Fe}(\mathrm{C}(\mathrm{OH}) \mathrm{O})]^{-}$. A second proton-donor then delivers the second proton to convert protonated carbon dioxide into water and a $\mathrm{CO}$ bound iron complex $[\mathrm{Fe}(\mathrm{CO})]^{0}$. We tested two different proton donors, namely phenol and $\mathrm{H}_{3} \mathrm{O}^{+}$for steps III and IV in the cycle. Release of $\mathrm{CO}$ upon final reduction brings the cycle back to the reactant complex.

Reaction cycle for $\mathrm{CO}_{2}$ reduction. Firstly, we focused our work on the individual driving forces for the reaction steps in Scheme 2, namely step I, II, III, IV and V. To this end, we optimized the geometries of each individual compound in the reactions in all available spin states and calculated the reaction energy between the lowest energy states. Three density functional theory methods were employed for these sets of reactions, namely B3LYP, PBEO and B3LYPD3. As iron-complexes can appear in a variety of different spin states depending on the oxidation state, we calculated all possible spin states for each structure, namely the doublet and quartet spin state for the [Fe] complexes and triplet and quintet spin for all other structures. In the past it was shown that the choice of the density functional method occasionally affects the spin-state ordering of metal complexes and the ordering and relative energies changes vary with different methods. ${ }^{48,49}$ Thus, for a manganese(V)-oxo porphyrinoid system several low-lying spinstates were calculated and with the B3LYP method the singlet and triplet spin states were found to be within $1 \mathrm{kcal}$ $\mathrm{mol}^{-1}$, while with pure density functional methods, such as PBEO and BLYP, the energy gap was close to $10 \mathrm{kcal} \mathrm{mol}^{-}$ 150 These spin-state orderings and relative energies are important as it was shown that heme and nonheme iron(IV)-oxo complexes can react via two-state or multistate-reactivity patterns through close-lying spin-state surfaces and free energies of activation of comparable value on two spin state surfaces. ${ }^{51,52}$ Nevertheless, in the cycle from Scheme 2, all [Fe] complexes regarded of the chosen methodology are in a quartet spin state, whereas all calculations on $[\mathrm{Fe}(\mathrm{C}(\mathrm{OH}) \mathrm{O})]^{-}$and $[\mathrm{Fe}(\mathrm{CO})]^{0}$ identify a quintet spin ground state. Hence, the chemical system described here shows little sensitivity to the choice in density functional method. 
Table 1. Reaction free energies $(\Delta \mathrm{G})$ calculated for different models and methods. ${ }^{a, b, c}$

B3LYP

$\begin{array}{lcc}\text { Model: }^{d} & \text { large } & \text { small } \\ \text { Reaction step I: } & -61.2 & -58.1 \\ \text { Reaction step II } & 11.3 & 10.1 \\ \text { Reaction step III } & -11.8 & -13.8 \\ \text { Reaction step IV } & -14.4 & -19.6 \\ \text { Reaction step V } & -82.8 & -79.4\end{array}$

PBEO

$\begin{array}{cc}\text { large } & \text { small } \\ -64.9 & -60.0 \\ 5.6 & 3.0 \\ -9.5 & -12.2 \\ -5.7 & -12.4 \\ -69.8 & -67.8\end{array}$

B3LYP-D3

$\begin{array}{cc}\text { large } & \text { small } \\ -49.9 & -61.7 \\ -2.3 & 9.2 \\ -5.0 & -5.7 \\ -2.5 & -10.6 \\ -84.1 & -76.0\end{array}$

$a$. Individual reaction steps for the cycle in Scheme 2. ${ }^{b}$. Data obtained at BS2//BS1 with ZPE, thermal, entropic and solvent corrections included. ${ }^{c}$. Data in kcal mol ${ }^{-1}$. ${ }^{d}$ The large model contains an ortho-2-amide-TPP ligand and the small model TPP.

We tested two porphyrin ligand systems with either TPP or ortho-2-amide-TPP to explore the second coordination sphere effect of the system. Overall, the individual reaction energetics are very similar for most steps despite the change of equatorial ligand and the introduction of the ortho-2-amide substituent to one of the phenyl groups. Energies for the individual reaction steps with respect to the lowest energy spin state of each structure for the cycle shown in Scheme 2 are given in Table 1 and will be discussed in detail in the following.

The cycle starts from the $[\mathrm{Fe}]^{-}$complexes, which are in a quartet spin ground state with the doublet spin state higher in free energy for the ortho-2-amide-TPP system by 2.2 , 4.9 and $7.4 \mathrm{kcal} \mathrm{mol}^{-1}$ as calculated with B3LYP, PBEO and B3LYP-D3, respectively. As such the spin state ordering is not affected by the choice of the density functional method. The reduction of the $[\mathrm{Fe}]^{-}$center is exergonic by 61.2 (64.9) [49.9] $\mathrm{kcal} \mathrm{mol}^{-1}$ as calculated for the large model with B3LYP (PBEO) [B3LYP-D3]. The reduction potentials of the smaller model with TPP ligand are calculated to be $58.1,60.0$ and $61.7 \mathrm{kcal} \mathrm{mol}^{-1}$. As follows dispersion affects the reduction potential with a large amount and reduces it by about $11 \mathrm{kcal} \mathrm{mol}^{-1}$. This is caused by the ortho-2-amide substituent as the system with the simple TPP ligand system gives a reduction potential at UB3LYP-D3 close to the non-dispersion corrected value. Experimental work on [Fe(TPP)] and [Fe(ortho-2-amide-TPP)] gave reduction potentials that are within $0.03 \mathrm{~V}$ of each other and, therefore, the energy difference between the TPP and ortho-2-amide-TPP systems should be small. ${ }^{30}$ Moreover, if we calculate the reduction step for the large system with respect to the ferrocene/ferrocinium couple at B3LYP we find a redox change of $2.62 \mathrm{eV}$ for step 1 , which is in reasonable quantitative agreement with the experimental value obtained. ${ }^{30}$ The small change in redox potential upon replacement of ortho-2-amide-TPP by TPP is indeed confirmed with our calculations using the B3LYP and PBEO methods; however, dispersion corrected reduction potentials overestimate the effect of the ortho-2-amide group and widens the gap. Consequently, B3LYP-D3 appears less suitable for the calculation of iron-porphyrin reduction potentials than B3LYP or PBEO. The observation that iron porphyrin systems are easily reduced links well with experimental work on biomimetic porphyrin systems and heme enzymes. ${ }^{53-55}$

In the next step we bind $\mathrm{CO}_{2}$ to the reaction complex and calculated the driving force with respect to isolated reactants. A similar effect of dispersion is seen on the $\mathrm{CO}_{2}$ binding process as that reported on the porphyrin reduction step, where we see a stabilization and larger driving force with dispersion included. Thus, we calculate an exergonic process by $-2.3 \mathrm{kcal} \mathrm{mol}^{-1}$ with UB3LYP-D3, whereas it is endergonic at UB3LYP and UPBEO levels of theory (Table 1). Again, the small model complex follows the same trend for all methods and only the system with ortho-2-amide linkage gives an exergonic $\mathrm{CO}_{2}$ binding process. Despite the fact that the driving forces are thermoneutral or endergonic with most methods and models, actually - as expected - the $\mathrm{CO}_{2}$ bound complexes are local minima on the potential energy surface and $\mathrm{CO}_{2}$ is chemically bound with chemical bonds and no release of $\mathrm{CO}_{2}$ during the optimizations is found. As such the $\mathrm{CO}_{2}$ binding energy is overestimated with all methods. This may be because the entropy contribution for this reaction step is very large and in the direction of isolated species. Previously, work on biomimetic reaction mechanisms showed that in comparison to experimental entropies of activation, the gas-phase calculated entropy is overestimates the real value by about $50 \%{ }^{45}$

Subsequently, the protonation of bound $-\mathrm{CO}_{2}$, i.e. in complex $\left[\mathrm{Fe}\left(\mathrm{CO}_{2}\right)\right]^{2-}$ was investigated using two different proton sources, namely phenol and $\mathrm{H}_{3} \mathrm{O}^{+}$. Obviously, due to its higher $\mathrm{pK}_{\mathrm{a}}$ the proton transfer from $\mathrm{H}_{3} \mathrm{O}^{+}$is more exergonic than the one using phenol, but the overall trends are the same. With phenol as a proton source the reaction is slightly exergonic, i.e. $-11.8(-9.5)[-5.0] \mathrm{kcal} \mathrm{mol}^{-1}$ for the ortho-2-amide-TPP as calculated with B3LYP (PBEO) [B3LYP-D3], respectively. As such, the density functional 
theory method seems to have only a small effect on the proton transfer process. Interestingly, the proton transfer is more exergonic for the TPP system than for the ortho-2amide ligand system, although the energy differences are within $3 \mathrm{kcal} \mathrm{mol}^{-1}$. Hence, the proton transfer is more subtle and directed with the larger model than with the small model complex.

In the second proton transfer, the difference between the ortho-2-amide-TPP and TPP ligand systems is larger than that seen for the first proton transfer. All methods predict the second proton transfer to be more than $10 \mathrm{kcal}$ $\mathrm{mol}^{-1}$ exergonic for the small model, but much smaller valves are found for the larger model. This implies that the second proton transfer may be an equilibrium step and hence is slow. Nevertheless, it is clear that both protontransfer steps will be $\mathrm{pH}$ dependent and the kinetics of these steps will depend on the acid concentration.

The final step for $\mathrm{CO}$ release upon reduction is highly exergonic with all methods. This step gives the least effect of the choice of the porphyrin models as the energy differences between the TPP and ortho-2-amide-TPP systems are all within a few $\mathrm{kcal} \mathrm{mol}^{-1}$. Interestingly, the effect of dispersion on this reaction step is very small and the energies obtained at B3LYP and B3LYP-D3 level of theory are almost the same. Overall, the reaction cycle displayed in Scheme 2 and Table 1 mostly has exergonic reaction steps and hence should be thermodynamically feasible pathway for $\mathrm{CO}_{2}$ reduction. To gain insight into the individual reaction steps we analyzed the structure, electronic properties and kinetics in more detail.

Electronic configurations of structures. Table 1 only reports relative energies with respect to the most stable configuration and spin state for each individual structure. For all systems; however, we calculated alternative spin state structures as well (see Supporting Information). Thus, the $[\mathrm{Fe}]^{-}$system has close lying doublet and quartet spin states with configuration $\delta_{x 2-y_{2}}{ }^{2} 3 d_{x z}{ }^{2} 3 d_{y z}{ }^{\uparrow} 3 d_{z 2}{ }^{\uparrow} \sigma_{x y}^{*}{ }^{0} e_{g}{ }^{* \downarrow}$ and $\delta_{x 2-y 2}{ }^{2} 3 d_{x z}{ }^{2} 3 d_{y z}{ }^{\uparrow} 3 d_{z 2}{ }^{\uparrow} \sigma_{x y}^{*}{ }^{0} e_{y}{ }^{* \uparrow}$, respectively. These orbital occupations have the porphyrin in the $x y$-plane and the $z$-axis perpendicular to it. Note, we define the $x$ - and $y$-axis as passing through an $\mathrm{Fe}-\mathrm{N}$ bond. As such the $\delta_{x 2-y 2}$ orbital is the nonbonding $3 \mathrm{~d}$-type orbital in the plane of the porphyrin ring, while the $\sigma_{x y}^{*}$ orbital is the antibonding orbital for the $\sigma^{*}$-interactions of the nitrogen atoms of the porphyrin with the metal $3 d_{x y}$ orbital ${ }^{56,57}$

In the absence of axial and equatorial ligands to the $[\mathrm{Fe}]^{-}$and $[\mathrm{Fe}]^{2-}$ complexes, the $3 \mathrm{~d}_{\mathrm{xz}}, 3 \mathrm{~d}_{\mathrm{yz}}$ and $3 \mathrm{~d}_{\mathrm{z} 2}$ atomic orbitals on iron are virtually nonbonding. Furthermore, the $\mathrm{e}_{\mathrm{g}}{ }^{*}$ orbital (Figure 1) is one orbital of a pair of $\pi$-type $e_{g}$ orbitals on the porphyrin manifold and is typically virtual in an isolated porphyrin. However, in the reduced [Fe(TPP)] and [Fe(ortho-2-amide-TPP)] $]^{-}$structures the pair of $\mathrm{e}_{\mathrm{g}}$ orbitals is occupied with one electron. The $\delta$ and $\sigma^{*}$ orbitals, by contrast, are dominant metal-based orbitals and contain large $3 \mathrm{~d}(\mathrm{Fe})$ atomic contributions. The orbital occupation of the doublet and quartet spin states, therefore, implicates that the porphyrin is reduced rather than the metal and the actual configuration of the complex is [ $\left.\mathrm{Fe}^{\prime \prime}\left(\mathrm{TPP}^{--}\right)\right]^{-}$ rather than $\left[\mathrm{Fe}^{\prime}(\mathrm{TPP})\right]^{-}$. The group spin densities (Supporting Information Table S7) give a value of about -1 for all doublet spin states and +1 for the quartet spin states on the porphyrin manifold, which confirms the electronic assignment. Our observations are in agreement with experimental spectroscopic studies in combination with highlevel ab initio calculations on the [Fe(TPP)] complex that found the same electronic configuration as reported here. ${ }^{58,59}$ Earlier work using DFT and QM/MM calculations on a cytochrome $\mathrm{P} 450$ reduced state with axial cysteinate group also found the same state. ${ }^{60}$

Reduction of the $[\mathrm{Fe}]^{-}$complex to form the $[\mathrm{Fe}]^{2-}$ system leads to an electronic configuration with a doubly reduced porphyrin manifold, i.e. an electronic state $\left[\mathrm{Fe}^{\prime \prime}\left(\mathrm{TPP}^{2-}\right)\right]^{2-}$. An analysis of the group spin densities (Supporting Information Table S8) shows that the spin density on the porphyrin group has almost disappeared and the spin on iron has stayed the same upon reduction. This is in agreement with previous studies on analogous complexes that reported a ligand-based reduction step. ${ }^{2 b, 58,59}$

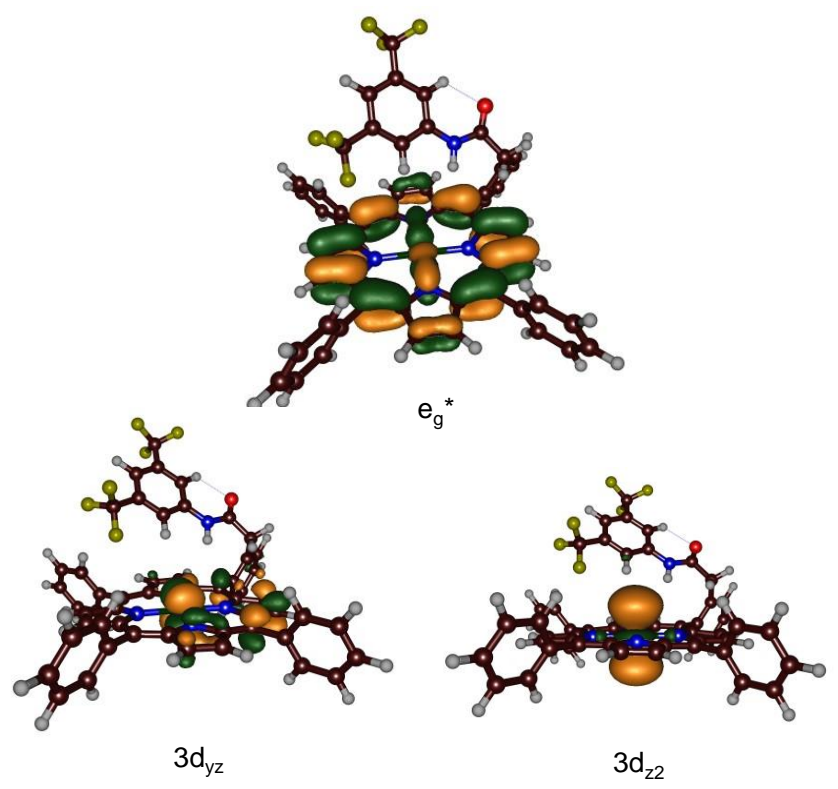

Figure 1. Singly occupied orbitals of [Fe] $]^{-}$. 


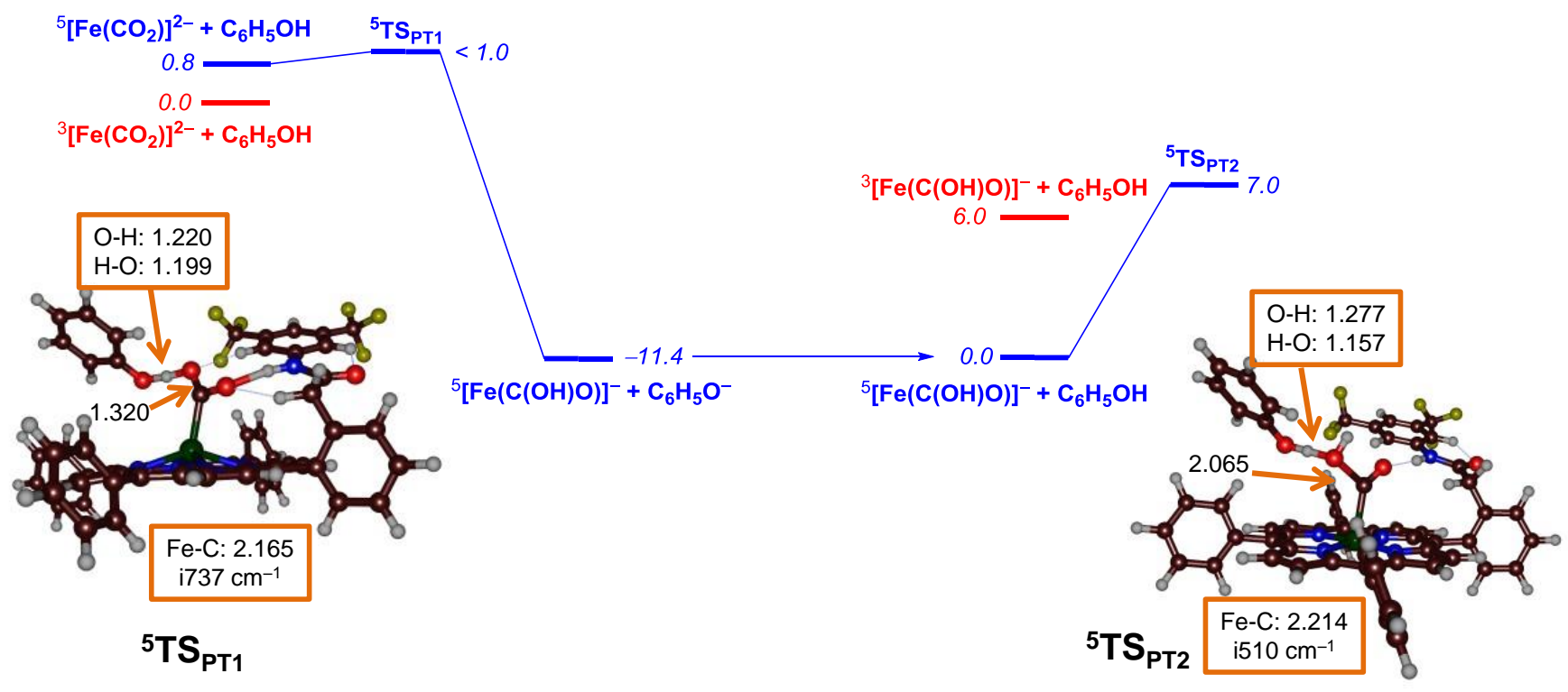

Figure 2. Proton transfer reaction mechanisms from ${ }^{3,5}\left[\mathrm{Fe}\left(\mathrm{CO}_{2}\right)\right]^{2-}$ from phenol as calculated with UB3LYP in Gaussian-09. Relative free energies are given in kcal mol${ }^{-1}$ and contain zero-point, thermal and entropic corrections at $298 \mathrm{~K}$. Optimized geometries give bond lengths in angstroms and the imaginary frequency in $\mathrm{cm}^{-1}$.

Subsequently, $\mathrm{CO}_{2}$ binds to the $[\mathrm{Fe}]^{2-}$ complex. These $\mathrm{CO}_{2}$ bound complexes remain in the triplet spin ground state, but the energy separation with the quintet spin state widens considerably at B 3 LYP and PBEO level of theory for the ortho-2-amide system to 13.8 and $7.9 \mathrm{kcal} \mathrm{mol}^{-1}$, while B3LYP-D3 gives the two states within $1 \mathrm{kcal} \mathrm{mol}^{-1}$. The spin densities describe these states as an iron(II) with porphyrin anion radical, with spin density of 0.84 on the ortho-2-amide-TPP unit, 1.64 on iron and -0.48 on $\mathrm{CO}_{2}$ (B3LYP result). As such, $\mathrm{CO}_{2}$ binding leads to polarization of the charge and spin and partial electron transfer from metal to $\mathrm{CO}_{2}$ group. The overall structure and electronic configuration of the $\left[\mathrm{Fe}\left(\mathrm{CO}_{2}\right)\right]^{2-}$ complexes resembles those reported for iron-carbene complexes in the literature. ${ }^{56,61-65}$

In the next stage of the reaction a proton transfer occurs, therefore, we created a model of the $\mathrm{CO}_{2}$ bound ironporphyrin with a nearby proton donor, i.e. a phenol group as phenol is used in the experimental system as a proton source. ${ }^{30}$ The $\left[\mathrm{Fe}\left(\mathrm{CO}_{2}\right) \text { (ortho-2-amide-TPP) }\right]^{2-}$ complex has spin densities that are slightly different from those of the isolated complex with spin density of 0.93 on the ortho-2amide-TPP unit, 1.37 on iron and -0.29 on $\mathrm{CO}_{2}$ (B3LYP result). As such the hydrogen bonding interaction of the phenol group affects the charge and spin distributions of the ligand bound to the metal dramatically and polarizes the charge and spin. Moreover, it influences the structure and a small distortion from planarity in the porphyrin system is observed.

Figure 2 shows optimized geometries along the reaction cycle of Scheme 2 above. On the left-hand-side of Figure
2 the first proton transfer is displayed, which has a small barrier via ${ }^{5} \mathrm{TS}_{\mathrm{PT}}$ on the quintet spin state of smaller than 1 $\mathrm{kcal} \mathrm{mol}^{-1}$ above the $\mathrm{CO}_{2}$ bound complex. Consequently, the first proton transfer will happen almost instantaneously and even a weak acid like phenol can deliver a proton efficiently. Nevertheless, the transition state was fully characterized with an imaginary frequency of i737 $\mathrm{cm}^{-1}$ representing the proton-transfer motion. This transition state is very central with almost equal distances of the proton with the donor and acceptor oxygen atoms with PhO-$\mathrm{H}$ distance of $1.220 \AA$ and $\mathrm{H}--\mathrm{OCO}$ distance of $1.199 \AA$. On the triplet spin state no barrier could be located and the geometry scan for $\mathrm{O}-\mathrm{H}$ bond formation had a continuous increase in energy; hence the proton transfer is not feasible on the triplet spin state.

The first proton transfer step converges to an $\left[\mathrm{Fe}((\mathrm{C}(\mathrm{OH}) \mathrm{O})]^{-}\right.$complex. We took the final optimized product complex of the first proton transfer reaction and replaced phenolate with phenol to create the starting point for the second proton transfer reaction, namely $\left[\mathrm{Fe}(\mathrm{C}(\mathrm{OH}) \mathrm{O})---\mathrm{C}_{6} \mathrm{H}_{5} \mathrm{OH}\right]^{-}$. All methods (B3LYP, PBEO, B3LYP-D3) and models (TPP vs ortho-2-amide-TPP) give a quintet spin ground state with the triplet spin state at least $5 \mathrm{kcal} \mathrm{mol}^{-1}$ higher in free energy. Next, the proton transfer from phenol to $\mathrm{HOCO}$ was calculated, whereby the proton was delivered to the $\mathrm{OH}$ group of the $\mathrm{HOCO}$ moiety to form water and $\mathrm{CO}$. Transition states $\left({ }^{3,5} \mathrm{TS}_{\mathrm{PT} 2}\right)$ were located for these proton transfer pathways. A free energy of activation of $\Delta \mathrm{G}^{\ddagger}=7.0 \mathrm{kcal} \mathrm{mol}^{-1}$ for ${ }^{5} \mathrm{TS}_{\mathrm{PT} 2}$ is calculated at B3LYP level of theory, while the triplet spin transition state is well higher $\left(20.3 \mathrm{kcal} \mathrm{mol}^{-1}\right)$. 


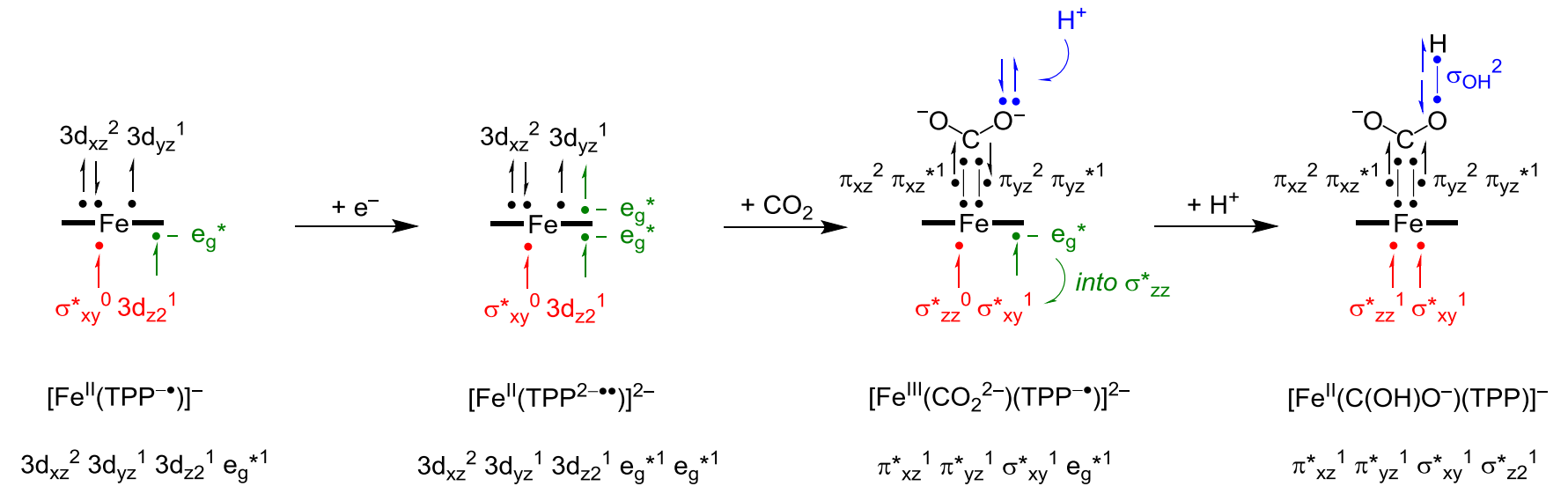

Figure 3. Electron transfer processes during the $\mathrm{CO}_{2}$ reduction catalytic cycle. Dots represent electrons, up- and down-arrows designate up- and down-spin electrons and a line in between two dots is a bonding orbital.

The quintet spin transition state $\left({ }^{5} \mathrm{TS}_{\mathrm{PT}}\right)$ has a large imaginary frequency typical for proton transfer reaction seen before, ${ }^{66-69}$ with a magnitude of $i 510 \mathrm{~cm}^{-1}$ for the correct mode. Similar to the transition state for the first proton transfer $\left({ }^{5} \mathrm{TS}_{\mathrm{PTI}}\right)$, the second proton transfer transition state $\left({ }^{5} \mathrm{TS}_{\mathrm{PT} 2}\right)$ is very central with a $\mathrm{PhO}--\mathrm{H}$ distance of $1.277 \AA$

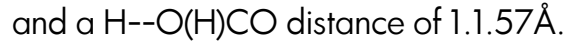

Overall, the calculations show that the two proton transfer steps have low-energy transition states and should proceed very rapidly in a phenol solution. Obviously these barriers will be even lower and the driving forces more exergonic when stronger acids than phenol are used, such as $\mathrm{H}_{3} \mathrm{O}^{+}$. Indeed, we find much larger exergonicities for the reaction with $\mathrm{H}_{3} \mathrm{O}^{+}$as a proton source than those with phenol as proton source.

Optimized geometries of ${ }^{3,5} \mathrm{TS}_{\text {PT2 }}$ with a TPP ligand rather than ortho-2-amide-TPP ligand are shown in Figure S12 (Supporting Information). All distances are within $0.1 \AA$ of those calculated for the analogous structures with ortho2amide-TPP ligand system, while they are energetically within $2 \mathrm{kcal} \mathrm{mol}^{-1}$. Therefore, the hydrogen bonding donation of the ortho-2-amide group has little structural and energetic effects on the proton transfer steps in the reaction mechanism.

Electron transfer mechanisms. To understand the intricate details of the electron transfer processes during the $\mathrm{CO}_{2}$ reduction cycle, we describe the individual steps with valence bond structures in Figure 3, which were previously used to describe electron transfer mechanisms during chemical reaction processes. ${ }^{70-72}$ As explained above and in the literature, ${ }^{58-60}$ the $[\mathrm{Fe}]^{-}$complexes are in an electronic configuration with the metal in oxidation state $\mathrm{Fe}$ (II) coupled with a ligand anion radical, i.e. should be considered as $\left[\mathrm{Fe}^{\prime \prime}\left(\mathrm{TPP}^{-\bullet}\right)\right]^{-}$. Upon further reduction to the $[\mathrm{Fe}]^{2-}$ state another electron is added to the porphyrin set of orbitals, so that its occupation becomes $3 d_{x z}{ }^{2} 3 d_{y z}{ }^{1} 3 d_{z 2}{ }^{1} e_{g}{ }^{* 1}$ $\mathrm{e}_{\mathrm{g}}{ }^{* 1}$. Therefore, the orbital assignment and group spin densities ascribe the $[\mathrm{Fe}]^{-}$and $[\mathrm{Fe}]^{2-}$ states as $\left[\mathrm{Fe}^{\prime \prime}\left(\mathrm{TPP}^{-0}\right)\right]^{-}$ and $\left[\mathrm{Fe}^{\prime \prime}\left(\mathrm{TPP}^{2-\bullet \bullet}\right)\right]^{2-}$, respectively.

Next, $\mathrm{CO}_{2}$ binds to the $[\mathrm{Fe}]^{2-}$ complex, which results in the formation of an iron-carbon bond between the ironporphyrin and the incoming $\mathrm{CO}_{2}$ group. This results in the formation of a new set of molecular orbitals for the distal interactions to the iron. Thus, the $3 d_{x z}$ and $3 d_{y z}$ atomic orbitals on Fe form interactions with a doubly occupied $2 \mathrm{p}_{\mathrm{C}}$ orbital on $\mathrm{CO}_{2}$ to give two pair of three-electron bonds represented as $\pi_{\mathrm{xz}}{ }^{2} \pi_{\mathrm{xz}}^{*}{ }^{1}$ and $\pi_{\mathrm{yz}}{ }^{2} \pi^{*}{ }_{\mathrm{yz}}{ }^{1}$. Two of those electrons originate from $2 p_{c}$ electrons on $\mathrm{CO}_{2}$ that couple with the $3 d_{x z}{ }^{2} 3 d_{y z}{ }^{1}$ atomic orbitals of iron, while the final electron is promoted from one of the $\mathrm{e}_{\mathrm{g}}{ }^{*}$ orbitals. Consequently, the electronic configuration of $\left[\mathrm{Fe}\left(\mathrm{CO}_{2}\right)(\mathrm{TPP})\right]^{2-}$ is $\left[\mathrm{Fe}^{\prime \prime \prime}\left(\mathrm{CO}_{2}{ }^{2-}\right)\left(\mathrm{TPP}^{-\bullet}\right)\right]^{2-}$.

In the final step of the reaction mechanism in Figure 3 the first proton transfer takes place into the anion lone-pair on one of the oxygen atoms of $\mathrm{CO}_{2}{ }^{2-}$ to form the $\mathrm{C}(\mathrm{OH}) \mathrm{O}^{-}$ species. At the same time; however, an electron transfer occurs from the $e_{g}{ }^{*}$ porphyrin orbital into the $\sigma^{*}{ }_{z 2}$ orbital for the antibonding interaction along the $\mathrm{Fe}-\mathrm{C}$ bond. Little electronic changes are observed for the second proton transfer to form $\mathrm{CO}$ and $\mathrm{H}_{2} \mathrm{O}$. Spin densities calculated at B3LYP, PBEO and UB3LYP-D3 for structures [Fe((C(OH)O)] , $\left[\mathrm{Fe}((\mathrm{OH}) \mathrm{O})---\mathrm{C}_{6} \mathrm{H}_{5} \mathrm{O}\right]^{2-}$ and $[\mathrm{Fe}(\mathrm{CO})]$ in the quintet spin state give spin densities of about 3.7 on Fe and $0.2-0.3$ on the porphyrin scaffold. As such these structures only have metal-based singly occupied molecular orbitals $\left(\pi^{*}{ }_{\mathrm{xz}}\right.$, $\left.\pi_{y z}^{*}, \sigma_{z 2}^{*}, \sigma_{x y}^{*}\right)$ and no ligand radical. Furthermore, this implies that step IV in the cycle shown in Scheme 2 above is a pure proton transfer process and no electron transfer happens. 


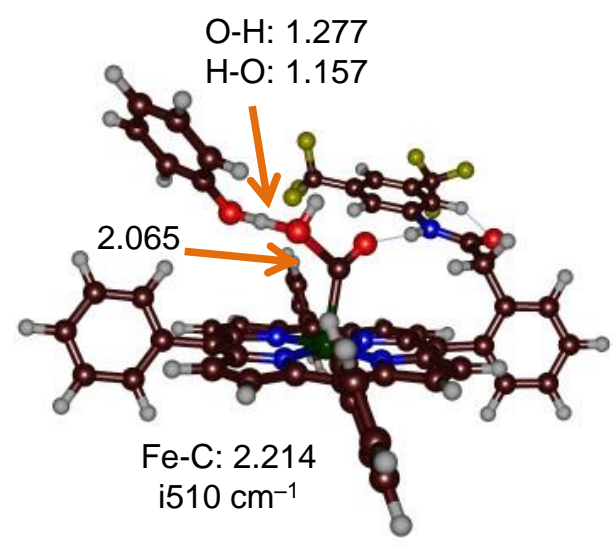

${ }^{5} \mathrm{TS}_{\mathrm{PT2} \text {,ortho-2-amide-TPP }}$

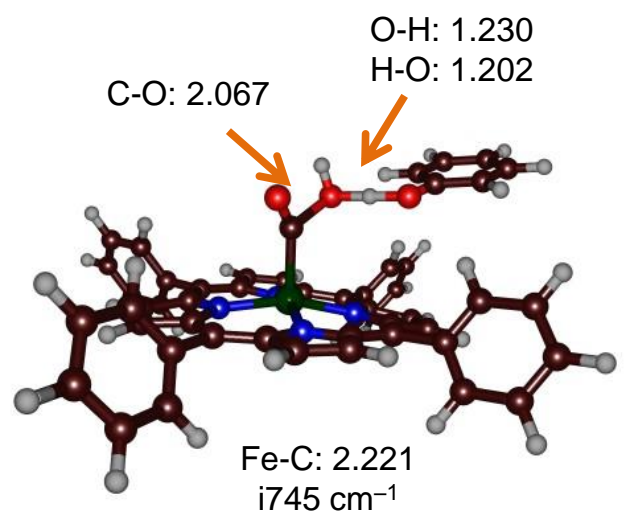

${ }^{5} \mathrm{TS}_{\mathrm{PT} 2, \mathrm{TPP}}$

Figure 4. Proton transfer transition states for the second proton transfer step with either ortho-2-amide-TPP (left) and TPP (right) ligand system. Calculations performed with UB3LYP in Gaussian-09. Optimized geometries give bond lengths in angstroms and the imaginary frequency in $\mathrm{cm}^{-1}$.

By contrast, step III in the $\mathrm{CO}_{2}$ reduction cycle should be considered as a proton-coupled electron-transfer as simultaneously to the proton transfer and electron is migrated from the porphyrin group to the metal.

Second-coordination sphere effects on reaction mechanism. In this work we investigate the $\mathrm{CO}_{2}$ reduction cycle starting from [Fe(TPP)] $]^{-}$and [Fe(ortho-2-amide-TPP)] and all intermediates and both proton transfer transition states were characterized for both models. In general, the individual reaction steps (Table 1) for the large versus the small model calculated with B3LYP and PBEO are within a few $\mathrm{kcal} \mathrm{mol}^{-1}$ and only step IV (second proton transfer) gives a larger driving force for the small model. With dispersion corrections included during the geometry optimizations the energy differences between the larger and smaller TPP models are much larger.

Using the B3LYP level of theory the proton transfer steps were investigated in detail and transition states ${ }^{3,5} \mathrm{TS}_{\mathrm{PT} 2}$ for the TPP and ortho-2-amide-TPP systems were found. Optimized geometries of the two transition state structures are given in Figure 4 for comparison. Energetically they are very similar with $\Delta G^{\ddagger}=7.0(20.3) \mathrm{kcal} \mathrm{mol}^{-1}$ for ${ }^{5} \mathrm{TS}_{\text {PT2 }}$ $\left({ }^{3} \mathrm{TS}_{\text {PT2 }}\right)$ with ortho-2-amide-TPP ligand, while $\Delta \mathrm{G}^{\ddagger}=5.2$ (19.6) $\mathrm{kcal} \mathrm{mol}^{-1}$, respectively, for the TPP ligated model. As such the second coordination sphere effect is small and has little effect on the kinetics of the reaction and the positioning of the substrate, oxidant and proton source.

Optimized geometries of ${ }^{5} \mathrm{TS}_{\text {PT2 }}$ with TPP and ortho-2amide-TPP are very similar (Figure 4). There is a small lengthening of the $\mathrm{H}-\mathrm{O}$ distance to the donor oxygen atom when there is a hydrogen bonded amide group present, which makes the transition state slightly earlier. Nevertheless, the $\mathrm{Fe}-\mathrm{C}$ and $\mathrm{C}-\mathrm{O}$ distances are within $0.01 \AA$ between the two transition state structures. Therefore, the ortho-2-amide-TPP ligand gives no major secondcoordination sphere effect and only leads to a minor destabilization of the transition states. No effect is seen on the electronic configurations of the individual structures and the group spin densities stay virtually the same. Most probably, the effect of the ortho-2-amide group in the ortho-2-amide-TPP system is by positioning the $\mathrm{CO}_{2}$ and trapping it into a fixed orientation. It can then be doubly protonated on the other oxygen atom of $\mathrm{CO}_{2}$ to form $\mathrm{CO}$ and water exclusively.

\section{Conclusions.}

In this work a computational study into the reduction of $\mathrm{CO}_{2}$ to $\mathrm{CO}$ on an iron-porphyrin center is reported. We tested two porphyrin types, namely with TPP and ortho-2amide-TPP as equatorial ligands. Density functional theory studies using a range of methods were done. The studies compare favorably with experiment and identify the [Fe] and $[\mathrm{Fe}]^{2-}$ complexes as an iron(II) ion coupled to a singly or doubly reduced porphyrin macrocycle. Subsequently, $\mathrm{CO}_{2}$ binding and protonation were investigated and show that the step should be considered as a proton-coupledelectron-transfer with electron migration from porphyrin to iron. A subsequent second protonation retains the electronic configuration of the metal porphyrin and leads to $\mathrm{CO}$ and water. Our study shows minor sensitivity of the density functional method on the reaction energies and thermodynamics. Overall we find that $\mathrm{CO}_{2}$ binding will be the rate determining step in the reaction cycle. 


\section{ASSOCIATED CONTENT}

Supporting Information. Tables with absolute and relative energies, group spin densities and charges as well as Figures with optimized geometries and geometry scans. In addition, Cartesian coordinates of all optimized geometries are supplied. This material is available free of charge via the Internet at http://pubs.acs.org.

\section{AUTHOR INFORMATION}

Corresponding Author

* sam.devisser@manchester.ac.uk (SPdV)

Author Contributions

The manuscript was written through contributions of all authors. / All authors have given approval to the final version of the manuscript.

\section{ACKNOWLEDGMENT}

The University of Manchester is acknowledged for support.

\section{ABBREVIATIONS}

DFT, density functional theory; ZPE, zero-point energy; CPCM, continuum polarized conductor model; TPP, tetraphenylporphyrin.

\section{REFERENCES}

(1) Shi, J.; Jiang, Y.; Jiang, Z.; Wang, X.; Wang, X.; Zhang, S.; Han, P.; Yang, C. Enzymatic conversion of carbon dioxide. Chem. Soc. Rev. 2015, 44, 5981-6000.

(2) Wagner, T.; Ermler, U.; Shima, S. The methanogenic $\mathrm{CO}_{2}$ reducing-and-fixing enzyme is bifunctional and contains 46 [4Fe-4S] clusters. Science 2016, 354, 114-117.

(3) Roger, M.; Brown, F.; Gabrielli, W.; Sargent, F. Efficient hydrogen-dependent carbon dioxide reduction by Escherichia coli. Curr. Biol. 2018, 28, 140-145.

(4) Ogawa, A.; Oohora, K.; Gua, W.; Hayashi, T. Electrochemical $\mathrm{CO}_{2}$ reduction by a cobalt bipyricorrole complex: decrease of an overpotential value derived from monoanionic ligand character of the porphyrinoid species. Chem. Commun. 2018, 55, 493-496.

(5) Fukuzumi, S.; Lee, Y.-M.; Ahn, H. S.; Nam, W. Mechanisms of catalytic reduction of $\mathrm{CO}_{2}$ with heme and nonheme metal complexes. Chem. Sci. 2018, 9, 6017-6034.

(6) Chatterjee, S.; Sengupta, K.; Mondal, B.; Dey, S.; Dey, A. Factors determining the rate and selectivity of $4 \mathrm{e}^{-} / 4 \mathrm{H}^{+}$electrocatalytic reduction of dioxygen by iron porphyrin complexes. Acc. Chem. Res. 2017, 50, 1744-1753.

(7) Fukuzumi, S.; Lee, Y.-M.; Nam, W. Kinetics and mechanisms of catalytic water oxidation. Dalton Trans. 2019, 48, 779-798.

(8) Matheu, R.; Ertem, M. Z.; Gimbert-Suriñach, C.; Sala, X.; Llobet, A. Seven coordinated molecular ruthenium-water oxidation catalysts: A coordination chemistry journey. Chem. Rev. 2019, 119, 3453-3471.

(9) Rao, H.; Bonin, J.; Robert, M. Toward visible-light photochemical $\mathrm{CO}_{2}$-to- $\mathrm{CH}_{4}$ conversion in aqueous solutions using sensitized molecular catalysis. J. Phys. Chem. C 2018, 122, 13834-13839.

(10) Liu, X.-F.; Li, X.-Y.; He, L.-N. Transition metalcatalyzed reductive functionalization of $\mathrm{CO}_{2}$. Eur. J. Org. Chem. 2019, 2437-2447.

(11) Laitar, D. S.; Müller, P.; Sadighi, J. P. Efficient homogeneous catalysis in the reduction of $\mathrm{CO}_{2}$ to CO. J. Am. Chem. Soc. 2005, 127, 17196-17197.

(12) Zhao, H.-Z.; Chang, Y.-Y.; Liu, C. Electrodes modified with iron porphyrin and carbon nanotubes: application to $\mathrm{CO}_{2}$ reduction and mechanism of synergistic electrocatalysis. J. Solid State Electrochem. 2013, 17, 1657-1664.

(13) Mohamed, E. A.; Zahran, Z. N.; Naruta, Y. Efficient electrocatalytic $\mathrm{CO}_{2}$ reduction with a molecular cofacial iron porphyrin dimer. Chem. Commun. 2015, 51, 16900-16903.

(14) Okabe, Y.; Lee, S. K.; Kondo, M.; Masaoka, S. Syntheses and $\mathrm{CO}_{2}$ reduction activities of $\mathrm{n}$-expanded/extended iron porphyrin complexes. J. Biol. Inorg. Chem. 2017, 22, 713725.

(15) Sinha, S.; Warren, J. J. Unexpected solvent effect in electrocatalytic $\mathrm{CO}_{2}$ to $\mathrm{CO}$ conversion revealed using asymmetric metalloporphyrins. Inorg. Chem. 2018, 57, 12650-12656.

(16) Sadique, A. R.; Brennessel, W. W.; Holland, P. L. Reduction of $\mathrm{CO}_{2}$ to $\mathrm{CO}$ using low-coordinate iron: Formation of a four-coordinate iron dicarbonyl complex and a bridging carbonate complex. Inorg. Chem. 2008, 47, 784-786.

(17) Sono, M.; Roach, M. P.; Coulter, E. D.; Dawson, J. H. Heme-containing oxygenases. Chem. Rev. 1996, 96, 28412888.

(18) Ortiz De Montellano, P. R., Ed., Cytochrome P450: Structure, Mechanism and Biochemistry, 3rd Ed., Kluwer Academic/Plenum Publishers, New York, 2005.

(19) Kadish, K. M.; Smith, K. M.; Guilard, R., Eds., Handbook Of Porphyrin Science, World Scientific Publishing Co., New Jersey, 2010.

(20) Meunier, B.; de Visser, S. P.; Shaik, S. Mechanism of oxidation reactions catalyzed by cytochrome P450 enzymes. Chem. Rev. 2004, 104, 3947-3980.

(21) Afanasiev, P.; Sorokin, A. B. $\mu$-Nitrido diiron macrocyclic platform: particular structure for particular catalysis. Acc. Chem. Res. 2016, 49, 583-593.

(22) Huang, X.; Groves, J. T. Beyond ferryl-mediated hydroxylation: 40 years of the rebound mechanism and $\mathrm{C}-\mathrm{H}$ activation. J. Biol. Inorg. Chem. 2017, 22, 185-207.

(23) de Visser, S. P. What drives the rate-determining step for oxygen atom transfer by heme Compound I? In Metallobiology Series No. 13. Dioxygen-dependent heme enzymes, IkedaSaito, M.; Raven, E. Eds.; Royal Society of Chemistry, Cambridge (UK), 2019, Chapter 5, pp $105-126$.

(24) de Visser, S. P.; Nam, W. High-valent iron-oxo porphyrins in oxygenation reactions. In Handbook of Porphyrin Science, Kadish, K. M.; Smith, K. M.; Guilard, R. (Eds.); World Scientific Publishing Co., New Jersey, 2010, Chapter 44, pp. 85140.

(25) Huang, X.; Groves, J. T. Oxygen activation and radical transformations in heme proteins and metalloporphyrins. Chem. Rev. 2018, 118, 2491-2553.

(26) Anxolabéhère-Mallart, E.; Bonin, J.; Fave, C.; Robert, M. Small-molecule activation with iron porphyrins using elec- 
trons, photons and protons: some recent advances and future strategies Dalton Trans. 2019, 48, 5869-5878.

(27) Sen, P.; Mondal, B.; Saha, D.; Rana, A.; Dey, A. Role of $2^{\text {nd }}$ sphere $\mathrm{H}$-bonding residues in tuning the kinetics of $\mathrm{CO}_{2}$ reduction to $\mathrm{CO}$ by iron porphyrin complexes. Dalton Trans. 2019, 48, 5965-5977.

(28) Margarit, C. G.; Schnedermann, C.; Asimow, N. G.; Nocera, D. G. Carbon dioxide reduction by iron hangman porphyrins. Organometallics 2019, 38, 1219-1223.

(29) Gotico, P.; Boitrel, B.; Guillot, R.; Sircoglou, M.; Quaranta, A.; Halime, Z.; Leibl, W.; Aukauloo, A. Secondsphere biomimetic multipoint hydrogen-bonding patterns to boost $\mathrm{CO}_{2}$ reduction of iron porphyrins. Angew. Chem. Int. Ed. 2019, 58, 4504-4509.

(30) Nichols, E. M.; Derrick, J. S.; Nistanaki, S. K.; Smith, P. T.; Chang, C. J. Positional effects of second-sphere amide pendants on electrochemical $\mathrm{CO}_{2}$ reduction catalyzed by iron porphyrins. Chem. Sci. 2018, 9, 2952-2960.

(31) de Visser, S. P. Trends in substrate hydroxylation reactions by heme and nonheme iron(IV)-oxo oxidants give correlations between intrinsic properties of the oxidant with barrier height. J. Am. Chem. Soc. 2010, 132, 1087-1097.

(32) Li, X.-X.; Postils, V.; Sun, W.; Faponle, A. S.; Solà, M.; Wang, Y.; Nam, W.; de Visser, S. P. Reactivity patterns of (protonated) Compound II and Compound I of Cytochrome P450: Which is the better oxidant? Chem. Eur. J. 2017, 23, 6406-6418.

(33) Pickl, M.; Kurakin, S.; Cantú Reinhard, F. G.; Schmid, P.; Pöcheim, A.; Winkler, C. K.; Kroutil, W.; de Visser, S. P.; Faber, K. Mechanistic studies of fatty acid activation by CYP152 peroxygenases reveal unexpected desaturase activity. ACS Catal. 2019, 9, 565-577.

(34) Latifi, R.; Sainna, M. A.; Rybak-Akimova, E. V.; de Visser, S. P. Does hydrogen bonding-donation to manganese(IV)oxo and iron(IV)-oxo oxidants affect the oxygen atom transfer ability? A computational study. Chem. Eur. J. 2013, 19, 40584068.

(35) Mukherjee, G.; Alili, A.; Barman, P.; Kumar, D.; Sastri, C. V.; de Visser, S. P. Interplay between steric and electronic effects: A joint spectroscopy and computational study of nonheme iron(IV)-oxo complexes. Chem. Eur. J. 2019, 25, 50865098.

(36) Gaussian 09, Revision D.01, Frisch, M. J.; Trucks, G. W.; Schlegel, H. B.; Scuseria, G. E.; Robb, M. A.; Cheeseman, J. R.; Scalmani, G.; Barone, V.; Mennucci, B.; Petersson, G. A. et al, Gaussian, Inc., C. T. Wallingford, 2009.

(37) Becke, A. D. Density-functional thermochemis-try. III. The role of exact exchange. J. Chem. Phys. 1993, 98, 56485652.

(38) Lee, C.; Yang, W.; Parr, R. G. Development of the ColleSalvetti correlation-energy formula into a functional of the electron density. Phys. Rev. B1988, 37, 785-789.

(39) Adamo, C.; Barone, V. Toward reliable density functional methods without adjustable parameters: The PBEO model. J. Chem. Phys. 1999, 110, 6158-6169.

(40) Grimme, S. Semiempirical hybrid density functional with perturbative second-order correlation. J. Chem. Phys. 2006, $124,034108$.

(41) Hay, P. J.; Wadt, W. R. Ab initio effective core potentials for molecular calculations. Potentials for the transition metal atoms Sc to Hg. J. Chem. Phys. 1985, 82, 270-283.
(42) Francl, M. M.; Pietro, W. J.; Hehre, W. J.; Binkley, J. S.; Gordon, M. S.; DeFrees, D. J.; Pople, J. A. Self-consistent molecular orbital methods. XXIII. A polarization-type basis set for second-row elements. J. Chem. Phys. 1982, 77, 3654-3658.

(43) Tomasi, J.; Mennucci, B.; Cammi, R. Quantum mechanical continuum solvation models, Chem. Rev. 2005, 105, 2999-3093.

(44) Sainna, M. A.; Kumar, S.; Kumar, D.; Fornarini, S.; Crestoni, M. E.; de Visser, S. P. A comprehensive test set of epoxidation rate constants by iron(IV)-oxo porphyrin complexes. Chem. Sci. 2015, 6, 1516-1529.

(45) Cantú Reinhard, F. G.; Faponle, A. S.; de Visser, S. P. Substrate sulfoxidation by an iron(IV)-oxo complex: benchmarking computationally calculated barrier heights to experiment. J. Phys. Chem. A 2016, 120, 9805-9814.

(46) Barman, P.; Upadhyay, P.; Faponle, A. S.; Kumar, J.; Nag, S. S.; Kumar, D.; Sastri, C. V.; de Visser, S. P. Deformylation reaction by a nonheme manganese(III)-peroxo complex via initial hydrogen atom abstraction. Angew. Chem. Int. Ed. 2016, 55, 11091-11095.

(47) Cantú Reinhard, F. G.; Barman, P.; Mukherjee, G.; Kumar, J.; Kumar, D.; Kumar, D.; Sastri, C. V.; de Visser, S. P. Keto-enol tautomerization triggers an electrophilic aldehyde deformylation reaction by a nonheme manganese(III)-peroxo complex. J. Am. Chem. Soc. 2017, 139, 18328-18338.

(48) Ghosh, A.; Taylor, P. R. High-level ab initio calculations on the energetics of low-lying spin states of biologically relevant transition metal complexes: A first progress report. Curr. Opin. Chem. Biol. 2003, 7, 113-124.

(49) Güell, M.; Luis, J. M.; Solà, M.; Swart, M. Importance of the basis set for the spin-state energetics of iron complexes. J. Phys. Chem. A 2008, 112, 6384-6391.

(50) Yang, T.; Quesne, M. G.; Neu, H. M.; Cantú Reinhard, F. G.; Goldberg, D. P.; de Visser, S. P. Singlet versus triplet reactivity in an $\mathrm{Mn}(\mathrm{V})-\mathrm{Oxo}$ species: Testing theoretical predictions against experimental evidence. J. Am. Chem. Soc. 2016, 138, 12375-12386.

(51) Shaik, S.; de Visser, S. P.; Ogliaro, F.; Schwarz, H.; Schröder, D. Two-state reactivity (TSR) mechanisms of hydroxylation and epoxidation by cytochrome P450 revealed by theory. Curr. Opin. Chem. Biol. 2002, 6, 556-567.

(52) de Visser, S. P.; Ogliaro, F.; Harris, N.; Shaik, S. Multistate epoxidation of ethene by cytochrome P450: a quantum chemical study. J. Am. Chem. Soc. 2001, 123, 3037-3047.

(53) Groves, J. T. High-valent iron in chemical and biological oxidations. J. Inorg. Biochem. 2006, 100, 434-447.

(54) Fukuzumi, S.; Fujioka, N.; Kotani, H.; Ohkubo, K.; Lee, Y.-M.; Nam, W. Mechanistic insights into hydride-transfer and electron-transfer reactions by a manganese(IV)-oxo porphyrin complex. J. Am. Chem. Soc. 2009, 131, 17127-17134.

(55) Carver, C. T.; Matson, B. D.; Mayer, J. M. Electrocatalytic oxygen reduction by iron tetra-arylporphyrins bearing pendant proton relays. J. Am. Chem. Soc. 2012, 134, 5444-5447.

(56) Cantú Reinhard, F. G.; Sainna, M. A.; Upadhyay, P.; Balan, G. A.; Kumar, D.; Fornarini, S.; Crestoni, M. E.; de Visser, S. P. A systematic account on aromatic hydroxylation by a cytochrome P450 model Compound I: A low-pressure mass spectrometry and computational study. Chem. Eur. J. 2016, 22, 18608-18619. 
(57) Postils, V.; Saint-André, M.; Timmins, A.; Li, X.-X.; Wang, Y.; Luis, J. M.; Solà, M.; de Visser, S. P. Quantum mechanics/molecular mechanics studies on the relative reactivities of Compound I and II in cytochrome P450 enzymes. Int. J. Mol. Sc. 2018, 19, 1974, doi:10.3390/ijms19071974.

(58) Römelt, C.; Song, J.; Tarrago, M.; Rees, J. A.; van Gastel, M.; Weyhermuiller, T.; DeBeer, S.; Bill, E.; Neese, F.; Ye, $\mathrm{S}$. Electronic structure of a formal iron( $(0)$ porphyrin complex relevant to $\mathrm{CO}_{2}$ reduction. Inorg. Chem. 2017, 56, 4745-4750.

(59) Römelt, C.; Ye, S.; Bill, E.; Weyhermuller, T.; van Gastel, M.; Neese, F. Electronic structure and spin multiplicity of iron tetraphenylporphyrins in their reduced states as determined by a combination of resonance Raman spectroscopy and quantum chemistry. Inorg. Chem. 2018, 57, 2141-2148.

(60) Porro, C. S.; Kumar, D.; de Visser, S. P. Electronic properties of pentacoordinated heme complexes in cytochrome P450 enzymes: Search for an Fe(l) oxidation state. Phys. Chem. Chem. Phys. 2009, 11, 10219-10226.

(61) Khade, R. L.; Zhang, Y. C-H insertions by iron porphyrin carbene: basic mechanism and origin of substrate selectivity. Chem. Eur. J. 2017, 23, 17654-17658.

(62) Wei, Y.; Tinoco, A.; Steck, V.; Fasan, R.; Yong Zhang, $Y$. Cyclopropanations via heme carbenes: basic mechanism and effects of carbene substituent, protein axial ligand, and porphyrin substitution. J. Am. Chem. Soc. 2018, 140, 1649-1662.

(63) Taxak, N.; Patel, B.; Bharatam, P. V. Carbene generation by cytochromes and electronic structure of heme-ironporphyrin-carbene complex: a quantum chemical study. Inorg. Chem. 2013, 52, 5097-5109.

(64) Torrent-Sucarrat, M.; Arrastia, I.; Arrieta, A.; Cossío, F. P. Stereoselectivity, different oxidation states, and multiple spin states in the cyclopropanation of olefins catalyzed by Fe-porphyrin complexes. ACS Catal. 2018, 8, 11140-11153.

(65) Cantú Reinhard, F. G.; de Visser, S. P. Oxygen atom transfer using an iron(IV)-oxo embedded in a tetracyclic $\mathrm{N}$ heterocyclic carbene system: How does the reactivity compare to Cytochrome P450 Compound I? Chem. Eur. J. 2017, 23, 29352944.

(66) de Visser, S. P.; Kumar, D.; Cohen, S.; Shacham, R.; Shaik, S. A predictive pattern of computed barriers for $\mathrm{C}-\mathrm{H}$ hydroxylation by Compound I of cytochrome P450. J. Am. Chem. Soc. 2004, 126, 8362-8363.

(67) Latifi, R.; Bagherzadeh, M.; de Visser, S. P. Origin of the correlation of the rate constant of substrate hydroxylation by nonheme iron(IV)-oxo complexes with the bond-dissociation energy of the $\mathrm{C}-\mathrm{H}$ bond of the substrate. Chem. Eur. J. 2009, 15, 6651-6662.

(68) Mukherjee, G.; Lee, C. W. Z.; Nag, S. S.; Cantú Reinhard, F. G.; Kumar, D.; Sastri, C. V.; de Visser, S. P. Dramatic rate-enhancement of oxygen atom transfer by an iron(IV)-oxo species by equatorial ligand field perturbations. Dalton Trans. 2018, 47, 14945-14957.

(69) Pattanayak, S.; Cantú Reinhard, F. G.; Rana, A.; Gupta, S. S.; de Visser, S. P. The equatorial ligand effect on the properties and reactivity of iron(V)-oxo intermediates. Chem. Eur. J. 2019, 25, 8092-810.

(70) Faponle, A. S.; Quesne, M. G.; de Visser, S. P. Origin of the regioselective fatty acid hydroxylation versus decarboxylation by a cytochrome $\mathrm{P} 450$ peroxygenase: What drives the reaction to biofuel production? Chem. Eur. J. 2016, 22, 5478-5483.
(71) Quesne, M. G.; Senthilnathan, D.; Singh, D.; Kumar, D.; Maldivi, P.; Sorokin, A. B.; de Visser, S. P. Origin of the enhanced reactivity of $\mu$-nitrido-bridged diiron(IV)-oxo porphyrinoid complexes over cytochrome P450 Compound I. ACS Catal. 2016, 6, 2230-2243.

(72) Kaczmarek, M. A.; Malhotra, A.; Balan, G. A.; Timmins, A.; de Visser, S. P. Nitrogen reduction to ammonia on a biomimetic mononuclear iron center: Insights into the nitrogenase enzyme. Chem. Eur. J. 2018, 24, 5293-5302. 
TOC Graphic:

$\stackrel{+}{\stackrel{+\mathrm{e}^{-}+\mathrm{CO}_{2}}{\longrightarrow}} \stackrel{{ }_{+\mathrm{H}^{+}}}{\longrightarrow}$ 